\title{
Penerapan Metode Moving Average dan Exponential Smoothing pada Peramalan Produksi Industri Garment
}

\author{
Rizal Rachman \\ STMIK Nusa Mandiri Jakarta \\ e-mail: rizalkhaizuran@gmail.com
}

\begin{abstract}
Abstrak
Permasalahan yang umum dihadapi oleh perusahaan adalah bagaimana meramalkan produksi barang di masa mendatang berdasarkan data yang telah direkam sebelumnya. perusahaan tersebut hanya memproduksi sesuai dengan pesanan, sehingga perusahaan hanya melakukan proses produksi sesuai jumlah yang diminta oleh para konsumen, jika terjadi kelebihan dalam produksi maka kelebihannya itu akan disimpan dalam stock, hal ini bertujuan untuk memenuhi permintaan konsumen yang sifatnya mendadak. Peramalan tersebut sangat berpengaruh pada keputusan manajemen untuk menentukan jumlah produksi barang yang harus disediakan oleh perusahaan, kondisi umum bisnis dan ekonomi, reaksi dan tindakan pesaing, tindakan pemerintah, kecenderungan pasar, siklus hidup produk, gaya dan mode, perubahan permintaan dan konsumen inovasi tekhnologi. Adapun tujuan dari penelitian ini yaitu untuk mengidentifikasi dan menganalisis hasil peramalan produksi garment dengan menggunakan metode peramalan Moving Average dan Exponential Smoothing. Untuk melakukan peramalan, semakin banyak data yang digunakan untuk peramalan maka semakin akurat pula hasil dari peramalan yang dilakukan. Hasil penelitian ini telah berhasil membuat sistem peramalan produksi garment. Sehingga lebih mudah dalam menentukan jumlah produksi garment pada periode tahun-tahun berikutnya.
\end{abstract}

Kata kunci: Peramalan, Moving Average, Exponential Smoothing.

\begin{abstract}
The common problem faced by the company is how to forecast the production of goods in the future based on previously recorded data. the company only produces in accordance with the order, so the company only make the production process according to the amount demanded by the consumer, if there is excess in production then the excess will be stored in stock, it aims to meet consumer demand that is sudden. Forecasting is very influential on management decisions to determine the amount of production of goods that must be provided by the company, general business and economic conditions, the reaction and action of competitors, government action, market trends, product life cycle, style and fashion, changes in demand and consumer technological innovation. The purpose of this study is to identify and analyze the results of forecasting garment production by using the method of forecasting Moving Average and Exponential Smoothing. To do the forecasting, the more data used for forecasting the more accurate the results of the forecasting. The result of this research has succeeded in making garment production forecasting system. So it is easier to determine the amount of garment production in the period of the following years.
\end{abstract}

Keywords: Forecasting, Moving Average, Exponential Smoothing. 


\section{Pendahuluan}

Salah satu aspek strategis perusahaan agar dapat bersaing dalam dunia bisnis adalah perencanaan tersedianya produk barang untuk memenuhi tuntutan pasar. Oleh karena itu peran seorang manajer untuk memahami dan kemampuan dalam meramalkan keadaan bisnis di masa depan sangat dibutuhkan. Permasalahan yang umum dihadapi oleh para manajer adalah bagaimana meramalkan penjualan baranag di masa mendatang berdasarkan data yang telah direkam sebelumnya. Peramalan tersebut sangat berpengaruh pada keputusan manajer untuk menentukan jumlah produksi barang yang harus disediakan oleh perusahaan (Setyowati, 2017).

Peramalan adalah seni atau ilmu untuk memperkirakan kejadian di masa depan. Hal ini dapat dilakukan dengan melibatkan pengambilan data historis dan memproyeksikannya ke masa mendatang dengan suatu bentuk model sistematis. Atau bisa juga dengan menggunakan kombinasi model matematis yang disesuaikan dengan pertimbangan yang baik dari seorang manajer (Render \& Heizer, 2009).

Peramalan

biasanya

diklasifikasikan berdasarkan horizon waktu masa depan yang dilingkupinya. Peramalan biasanya diklarifikasikan berdasarkan horizon waktu masa depan yang dilingkupinya. Horizon waktu terbagi menjadi beberapa kategori: 1. Peramalan Jangka Pendek Peramalan ini meliputi jangka waktu hingga satu tahun, tetapi umumnya kurang dari tiga bulan. Peramalan ini digunakan untuk merencanakan pembelian, penjadwalan kerja, jumlah tenaga kerja, penugasan kerja, dan tingkat produksi. 2. Peramalan Jangka Menengah Peramalan jangka menengah atau intermediate umumnya mencakup hitungan bulan hingga tiga tahun. Peramalan ini bermanfaat untuk 15 merencanakan penjualan, perencanaan dan anggaran produksi, anggaran kas, serta menganalisis bermacam-macam rencana operasi. 3. Peramalan Jangka Panjang Umumnya untuk perencanaan masa tiga tahun atau lebih. Peramalan jangka panjang digunakan untuk merencanakan produk baru, pembelanjaan modal, lokasi atau pengembangan fasilitas, serta penelitian dan pengembangan (litbang). (Taylor, 2009).

Peramalan diperlukan perhitungan yang akurat sehingga diperlukan peramalan yang tepat. Pada dasarnya terdapat dua pendekatan umum untuk mengatasi semua model keputusan untuk meramal (Nasution, 2008): 1. Peramalan Kualitatif Yaitu peramalan yang menggabungkan faktorfaktor seperti intuisi pengambilan keputusan, emosi, pengalaman pribadi, dan system nilai

2. Peramalan Kuantitatif Yaitu peramalan yang menggunakan satu atau lebih model matematis dengan data masa lalu dan variabel sebab akibat untuk meramalkan permintaan. Ada lima metode peramalan kuantitatif, yaitu metode pendekatan naif, metode rata-rata bergerak, metode penghalusan eksponential, penghalusan tren, dan regresi linear.

Sudah banyak penelitian yang dilakukan untuk mencari penyelesaian Forecasting dengan tujuan meramalkan proses produksi yang akan datang. Hasil penelitian oleh (Prasetio, 2014) menunjukkan bahwa metode terbaik untuk menentukan tingkat permintaan terhadap produk adalah metode Linear Regression karena memiliki nilai MAD dan MSE paling rendah diantara metode peramalan lainnya dan untuk membeli bahan baku utama yaitu PVC. PVC harus dibeli dalam jumlah yang tepat agar proses produksi dapat berjalan dengan baik dan efisien.. Penelitian lain yang dilakukan oleh (Wardah, 2016) menunjukkan pengumpulan dan pengolahan data serta analisa yang sudah dilakukan maka dapat kita bandingkan bahwa dari segi tingkat kesalahan serta perangkingan trend analysis mempunyai tingkat kesalahan yang lebih kecil dibandingkan dengan metode lainnya. Metode trend analysis mempunyai nilai MAD sebesar 161,3539, MSE sebesar 55744,16 , dan standar error sebesar 242,947, maka dapat disimpulkan bahwa metode terpilih adalah metode Trend Analysis. Berdasarkan analisa penetuan peramalan jumlah penjualan produk kripik pisang kemasan bungkus adalah sebanyak 1121,424 atau 1122 bungkus/bulan agar tidak mengalami kekurangan atau kelebihan persediaan produk kripik pisang untuk kemasan bungkus. Selanjutnya Penelitian (Andini, 2016) menghasilkan perbandingan hasil peramalan dengan data aktual penjualan di tahun 2015 pada 
pengujian mempunyai nilai presentase kesalahan (percentage error) dibawah $20 \%$ disetiap bulanya. Dikarenakan hasil peramalan menggunakan metode double exponential smoothing mendekati data aktual penjualan di tahun 2015. Analisa data aktual penjualan ATK tahun 2015 mempunyai pola data yang berunsur trend, maka metode yang cocok untuk meramalkan pola data yang berunsur trend adalah metode double exponential smoothing.

\section{Metode Penelitian}

Metode yang digunakan untuk menghitung peramalan produksi garment menggunakan jenis peramalan kuantitatif yaitu metode moving average dan metode exponential smhooting.

\section{Moving Average}

Rata-rata bergerak (Moving Average) adalah

suatu metode peramalan yang dilakukan dengan mengambil sekelompok nilai pengamatan, mencari nilai rata-rata tersebut sebagai ramalan untuk periode yang akan dating (Subagyo, 2008). Metode Moving Average mempunyai karakteristik khusus yaitu ;

- untuk menentukan ramalan pada periode yang akan datang memerlukan data historis selama jangka waktu tertentu. Misalnya, dengan 3 bulan moving average, maka ramalan bulan ke 5 baru dibuat setelah bulan ke 4 selesai/berakhir. Jika bulan moving averages bulan ke 7 baru bisa dibuat setelah bulan ke 6 berakhir.

- Semakin panjang jangka waktu moving average, efek pelicinan semakin terlihat dalam ramalan atau menghasilakan moving average yang semakin halus.

Persamaan matematis single moving averages adalah sebagai berikut:

$M t=F t+1$

$=\frac{Y t+Y t-1+Y t-2+\ldots+Y t-n+1}{n}$

Keterangan:

Mt $=$ Moving Average untuk periode $\mathrm{t}$ $\mathrm{Ft}+1=$ Ramalan Untuk Periode $\mathrm{t}+1$ $\mathrm{Yt}=$ Nilai Riil periode ke $\mathrm{t}$ $\mathrm{n} \quad=$ Jumlah batas dalam moving average

\section{Exponentials Smoothing}

Metode ini digunakan untu peramalan jangka pendek. Model mengasumsikan bahwa data berfluktuasi di sekitar nilai mean yang tetap, tanpa trend atau pola pertumbuhan konsisten. Tidak seperti Moving Average, Exponential Smoothing memberikan penekanan yang lebih besar kepada time series saat ini melalui penggunaan sebuah konstanta smoothing (penghalus). Konstanta smoothing mungkin berkisar dari 0 ke 1 . Nilai yang dekat dengan 1 memberikan penekanan terbesar pada nilai saat ini sedangkan nilai yang dekat dengan 0 memberi penekanan pada titik data sebelumnya (Herjanto, 2009).

$S t=\alpha * X t+(1-\alpha) * S t-1$

Rumus untuk Simple exponential smoothing adalah sebagai berikut:

Dimana:

$S_{t}=$ peramalan untuk periode $t$. $\mathrm{X}_{\mathrm{t}}+(1-\alpha)=$ Nilai aktual time series $\mathrm{F}_{\mathrm{t}-1}=$ peramalan pada waktu $\mathrm{t}-1$ (waktu sebelumnya)

$\alpha=$ konstanta perataan antara 0 dan 1

\section{Kesalahan Peramalan}

Tingkat kesalahan ramalan memberikan ukuran ketepatan dan ukuran untuk membandingkan metode-metode alternatif yang mungkin digunakan. Tingkat kesalahan peramalan bisa dihitung dengan Mean absolute Deviation dan Mean Squared Error (Yamit, 2008).

Mean absolute Deviation (MAD) adalah rata-rata nilai absolut dari kesalahan meramal, dengan tidak menghiraukan tanda positif serta negatifnya.

$M A D=\sum|A t-F t|$

Keterangan :

$\begin{array}{ll}\sum_{\mathrm{At}} & =\text { Jumlah } \\ \mathrm{Ft} & =\text { Data pengamatan periode } \mathrm{t} \\ & \end{array}$

Sedangkan Mean Squared Error ( MSE) adalah rata-rata perbedaan kuadrat antara nilai-nilai yang diramalkan dan nilai yang diamati MSE memberikan hukuman bagi kesalahan yang lebih besar, atau memperkuat pengaruh angka-angka kesalahan besar tetapi memperkecil angka. 
Kesalahan prakiraan yang lebih kecil dari suatu unit.

$$
M S E=\sum(A t-F t) 2
$$

Keterangan :

$$
\begin{array}{ll}
\sum_{\mathrm{At}} & =\text { Jumlah } \\
\mathrm{Ft} & =\text { Data pengamatan periode } \mathrm{t} \\
& =\text { Ramalan periode } \mathrm{t}
\end{array}
$$

\section{Hasil dan Pembahasan}

Pengumpulan data permintaan yang actual di peroleh dari perusahaan dengan mengacuh pada order yang diterima dari konsumen mulai dari bulan Januari 2017 - Desember 2017. Adapun data permintaan tersebut dapat dilihat pada tabel berikut ini :

Tabel 1

Data Permintaan Konsumen Tahun 2017

\begin{tabular}{|c|c|c|}
\hline No & Bulan & $\begin{array}{c}\text { Permintaan } \\
\text { Konsumen }\end{array}$ \\
\hline 1 & Januari & 108.216 \\
\hline 2 & Februari & 99.155 \\
\hline 3 & Maret & 90.700 \\
\hline 4 & April & 123.586 \\
\hline 5 & Mei & 91.761 \\
\hline 6 & Juni & 110.646 \\
\hline 7 & Juli & 135.077 \\
\hline 8 & Agustus & 61.545 \\
\hline 9 & September & 60.153 \\
\hline 10 & Oktober & 75.651 \\
\hline 11 & November & 77.060 \\
\hline 12 & Desember & 78.267 \\
\hline & Jumlah & 1.111 .817 \\
\hline
\end{tabular}

Sumber : Data Perusahaan

Berdasarkan data permintaan konsumen secara actual pada tahun 2017, maka dari data tersebut bisa dibuatkan Grafik sebagai berikut :

\section{Jumlah Produksi}

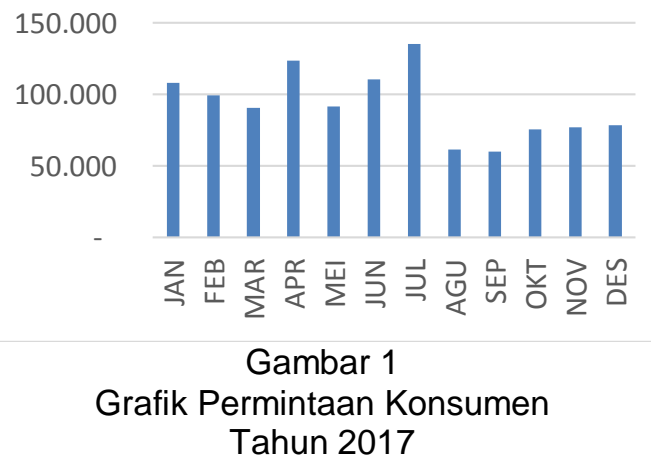

Data permintaan konsumen sangat fluktuatif pada tahun 2017. Untuk selanjutnya data akan diramalkan dengan dua metode peramalan yang mungkin bisa digunakan dalam menganalisis data. Dua metode tersebut adalah : Moving average dan exponential Smoothing. Adapun Moving Avarege menggunakan 3 bulanan dan 5 bulanan, Exponential Smoothing dengan $\alpha=0,1 ; \alpha=0,5 ;$ dan $\alpha=0,9$.

\section{Peramalan dengan motode Moving Average 3 bulanan}

Metode ini dihitung dengan cara: setiap diperoleh data aktual baru, maka rata-rata yang baru dapat dihitung dengan mengeluarkan data periode yang lama dan memasukkan data periode yang terbaru. Rata-rata yang baru digunakan sebagai prakiraan untuk periode yang akan datang.

$F_{t+1}=\frac{\sum_{i=t}^{t-N+1} X_{i}}{N}$
$\frac{X_{t}+X_{t-1}+\ldots+X_{t-N+1}}{N}$

Keterangan :

$\mathrm{X}_{1}=$ data pengamatan periode $\mathrm{t}$

$\mathrm{N}=$ jumlah deret waktu yang digunakan ( 3 bulan )

$\mathrm{F}_{t+1}=$ nilai prakiraan periode $\mathrm{t}+1$ ( berikutnya)

Ramalan permintaan konsumen untuk januari 2018

$F_{\text {januari } 2018}$

$$
\begin{aligned}
F_{t+1}= & \frac{75.651+77.060+78.267}{3} \\
= & \frac{230.978}{3} \\
= & 76.992,66
\end{aligned}
$$

Hasil peramalan Moving Average 3 bulanan sebagai berikut : 
Tabel 2

Hasil Peramalan Permintaan Konsumen Moving Average 3 bulanan

\begin{tabular}{|c|c|c|}
\hline Bulan & $\begin{array}{l}\text { Permintaan } \\
\text { Konsumen }\end{array}$ & Forecasting \\
\hline Januari & 108.216 & \\
\hline Februari & 99.155 & \\
\hline Maret & 90.700 & \\
\hline April & 123.586 & $99.357,00$ \\
\hline Mei & 91.761 & $104.480,33$ \\
\hline Juni & 110.646 & $102.015,67$ \\
\hline Juli & 135.077 & $108.664,33$ \\
\hline Agustus & 61.545 & $112.494,67$ \\
\hline September & 60.153 & $102.422,67$ \\
\hline Oktober & 75.651 & $85.591,67$ \\
\hline November & 77.060 & $65.783,00$ \\
\hline Desember & 78.267 & $70.954,67$ \\
\hline & & $76.992,67$ \\
\hline
\end{tabular}

Jadi ramalan permintaan konsumen untuk bulan januari 2018 dengan metode Moving Average 3 Bulanan adalah 76.992,67 pcs.

\section{Peramalan dengan motode Moving Average 5 bulanan}

Ramalan permintaan konsumen untuk januari 2018.

$F_{\text {januari } 2018}$

$$
\begin{aligned}
& F_{t+1}=\frac{61.545+60.153+75.651+77.060+78.267}{5} \\
& =\frac{352.676}{5} \\
& =70.535,20 \\
& F_{t+1}=\frac{\sum_{i=t}^{t-N+1} X_{i}}{N} \\
& =\frac{X_{t}+X_{t-1}+\ldots+X_{t-N+1}}{N}
\end{aligned}
$$

Keterangan :

$\mathrm{X}_{1}=$ data pengamatan periode $\mathrm{t}$

$\mathrm{N}$ = jumlah deret waktu yang digunakan ( 5 bulan )
$F_{t+1}=$ nilai prakiraan periode $t+1($ berikutnya)

Hasil peramalan Moving Average 5 bulanan sebagai berikut :

Tabel 3

Hasil Peramalan Permintaan Konsumen Moving Average 5 bulanan

\begin{tabular}{|c|c|c|}
\hline Bulan & $\begin{array}{c}\text { Permintaan } \\
\text { Konsumen }\end{array}$ & Forecasting \\
\hline Januari & 108.216 & \\
\hline Februari & 99.155 & \\
\hline Maret & 90.700 & \\
\hline April & 123.586 & \\
\hline Mei & 91.761 & \\
\hline Juni & 110.646 & $102.683,60$ \\
\hline Juli & 135.077 & $103.169,60$ \\
\hline Agustus & 61.545 & $110.354,00$ \\
\hline September & 60.153 & $104.523,00$ \\
\hline Oktober & 75.651 & $91.836,40$ \\
\hline November & 77.060 & $88.614,40$ \\
\hline Desember & 78.267 & $81.897,20$ \\
\hline & & $\mathbf{7 0 . 5 3 5 , 2 0}$ \\
\hline
\end{tabular}

Jadi ramalan permintaan konsumen untuk bulan januari 2018 dengan metode Moving Average 5 Bulanan adalah 70.535,20 pcs.

\section{Peramalan dengan motode Eksponential Smoothing. \\ Adapun alasan menggunaan $\alpha$} tersebut karena daerah $\alpha$ adalah antara 0 s/d 1, $\alpha=0,1$ mewakili awal data, $\alpha=0,5$ mewakili rata-rata, $\alpha=0,9$ mewakili data akhir.

$$
F_{-}(t+1)=\alpha * X t+(1-\alpha) * F t
$$

Keterangan :

$\mathrm{Xt}=$ data pengamatan periode $\mathrm{t}$

$\mathrm{F}_{\mathrm{t}+1}=$ nilai prakiraan periode $\mathrm{t}$

$\alpha=$ konstanta penghalusan 
$\alpha=0,1$

Forecastnya, Fmaret 2017

$=0,1 * 99.155+(1-0,1) * 108 \cdot 216$

$=9.915,50+(0,90) * 108.216$

$=9.915,50+97.394,40$

$=107.309,90$

Fjanuari 2018

$=0,1 * 78.267+(1-0,1) * 77.060$

$=7.826,70+(0,90) * 77.060$

$=7.826,70+69.354$

$=77 \cdot 180,70$

Tabel 4

Hasil Peramalan Permintaan Konsumen Eksponential Smoothing $\alpha=0,1$

\begin{tabular}{|c|c|c|}
\hline Bulan & $\begin{array}{c}\text { Permintaan } \\
\text { Konsumen }\end{array}$ & Forecasting \\
\hline Januari & 108.216 & - \\
\hline Februari & 99.155 & $107.309,90$ \\
\hline Maret & 90.700 & $98.309,50$ \\
\hline April & 123.586 & $93.988,60$ \\
\hline Mei & 91.761 & $120.403,50$ \\
\hline Juni & 110.646 & $93.649,50$ \\
\hline Juli & 135.077 & $113.089,10$ \\
\hline Agustus & 61.545 & $127.723,80$ \\
\hline September & 60.153 & $61.405,80$ \\
\hline Oktober & 75.651 & $61.702,80$ \\
\hline November & 77.060 & $75.791,90$ \\
\hline Desember & 78.267 & $77.180,70$ \\
\hline
\end{tabular}

Jadi ramalan

permintaan

konsumen untuk bulan januari 2018 dengan metode Eksponential Smoothing $\alpha=0,1$ adalah $77.180,70$ pcs.

\section{$\alpha=0,5$}

Forecastnya, Fmaret 2017

$=0,5 * 99.155+(1-0,5) * 108.216$

$=49.577,50+(0,50) * 108.216$

$=49.577,50+54.108$

$=103.685,50$

Fjanuari 2018

$=0,5 * 78.267+(1-0,5) * 77.060$

$=39.133,50+(0,50) * 77.060$
$=39.133,50+38.530$

$=77.663,50$

Tabel 5

Hasil Peramalan Permintaan Konsumen

Eksponential Smoothing $\alpha=0,5$

\begin{tabular}{|c|c|c|}
\hline Bulan & $\begin{array}{c}\text { Permintaan } \\
\text { Konsumen }\end{array}$ & Forecasting \\
\hline Januari & 108.216 & - \\
\hline Februari & 99.155 & $103.685,50$ \\
\hline Maret & 90.700 & $94.927,50$ \\
\hline April & 123.586 & $107.143,00$ \\
\hline Mei & 91.761 & $107.673,50$ \\
\hline Juni & 110.646 & $101.203,50$ \\
\hline Juli & 135.077 & $122.861,50$ \\
\hline Agustus & 61.545 & $98.311,00$ \\
\hline September & 60.153 & $60.849,00$ \\
\hline Oktober & 75.651 & $67.902,00$ \\
\hline November & 77.060 & $76.355,50$ \\
\hline Desember & 78.267 & $77.663,50$ \\
\hline
\end{tabular}

Jadi ramalan

permintaan konsumen untuk bulan januari 2018 dengan metode Eksponential Smoothing $\alpha=0,5$ adalah $77.663,50$ pcs.

$\alpha=0,9$

Forecastnya, Fmaret 2017

$=0,9 * 99.155+(1-0,9) * 108.216$

$=89.239,50+(0,10) * 108.216$

$=89.239,50+10.821,60$

$=100.061,10$

Fjanuari 2018

$=0,9 * 78.267+(1-0,9) * 77.060$

$=70.440,30+(0,10) * 77.060$

$=70.440,30+7.706$

$=78.146,30$ 
Tabel 6

Hasil Peramalan Permintaan Konsumen

Eksponential Smoothing $\alpha=0,9$

\begin{tabular}{|c|c|c|}
\hline Bulan & $\begin{array}{c}\text { Permintaan } \\
\text { Konsumen }\end{array}$ & Forecasting \\
\hline Januari & 108.216 & - \\
\hline Februari & 99.155 & $100.061,10$ \\
\hline Maret & 90.700 & $91.545,50$ \\
\hline April & 123.586 & $120.297,40$ \\
\hline Mei & 91.761 & $94.943,50$ \\
\hline Juni & 110.646 & $108.757,50$ \\
\hline Juli & 135.077 & $132.633,90$ \\
\hline Agustus & 61.545 & $68.898,20$ \\
\hline September & 60.153 & $60.292,20$ \\
\hline Oktober & 75.651 & $74.101,20$ \\
\hline November & 77.060 & $76.919,10$ \\
\hline Desember & 78.267 & $78.146,30$ \\
\hline
\end{tabular}

Jadi ramalan permintaan konsumen untuk bulan januari 2018 dengan metode Eksponential Smoothing $\alpha=0,9$ adalah $78.146,30$ pcs.

\section{Kesalahan Peramalan}

MAD yang diukur hanyalah besar kesalahan absolut. Biasanya efek dalam operasi yang kesalahannya sedikit tidaklah serius dan akan dihaluskan oleh permintaan atau kerja lembur. Kesalahan besar akan menjadi sulit, sedikit kesalahan besar sama jumlahnya dengan kesalahan kecil yang banyak. Akibatnya, metode pengukuran kesalhan yang menghukumi kesalahan besar perlu diperhitungkan. MSE merupakan tipe pengukuran kesalahan dengan mengalihkan masing-masing kesalahan peramalan dengan kuadratnya. Jadi dengan adanya penguadratan, kesalahan akan lebih mudah diketahui.
Tabel 7

Kesalahan peramalan metode Moving Averages 3 bulanan

\begin{tabular}{|c|c|c|}
\hline Bul & $\begin{array}{c}\text { Dev. Abslut } \\
|\mathrm{At}-\mathrm{Ft}|\end{array}$ & $\begin{array}{c}\text { Error }^{2} \\
(\mathrm{At}-\mathrm{Ft})^{2}\end{array}$ \\
\hline Jan & - & - \\
\hline Feb & - & - \\
\hline Mar & - & - \\
\hline Apr & $24.229,00$ & $587.044 .441,00$ \\
\hline Mei & $12.719,33$ & $161.781 .440,44$ \\
\hline Jun & $8.630,33$ & $74.482 .653,44$ \\
\hline Jul & $26.412,67$ & $697.628 .960,44$ \\
\hline Ags & $50.949,67$ & $2.595 .868 .533,44$ \\
\hline Sep & $42.269,67$ & $1.786 .724 .720,11$ \\
\hline Okt & $9.940,67$ & $98.816 .853,78$ \\
\hline Nov & $11.277,00$ & $127.170 .729,00$ \\
\hline Des & $7.312,33$ & $53.470 .218,78$ \\
\hline$\Sigma$ & $193.740,67$ & $6.182 .988 .550,44$ \\
\hline $\begin{array}{c}\text { MAD } \\
\text { dan } \\
\text { MSE }\end{array}$ & $\mathbf{2 1 . 5 2 6 , 7 4}$ & $\mathbf{6 8 6 . 9 9 8 . 7 2 7 , 8 3}$ \\
\hline
\end{tabular}

Tabel 8

Kesalahan peramalan metode Moving Averages 5 bulanan

\begin{tabular}{|c|c|c|}
\hline Bul & $\begin{array}{c}\text { Dev. Abslut } \\
\mid \text { At }- \text { Ft } \mid\end{array}$ & $\begin{array}{c}\text { Error }^{2} \\
(\text { At }-F t)^{2}\end{array}$ \\
\hline Jan & - & - \\
\hline Feb & - & - \\
\hline Mar & - & - \\
\hline Apr & - & - \\
\hline Mei & - & - \\
\hline Jun & 7962,4 & $63.399 .813,76$ \\
\hline Jul & 31907,4 & $1.018 .082 .174,76$ \\
\hline Ags & $48.809,00$ & $2.382 .318 .481,00$ \\
\hline Sep & $44.370,00$ & $1.968 .696 .900,00$ \\
\hline
\end{tabular}




\begin{tabular}{|c|c|c|}
\hline Okt & $16.185,40$ & $261.967 .173,16$ \\
\hline Nov & $11.554,40$ & $133.504 .159,36$ \\
\hline Des & $3.630,20$ & $13.178 .352,04$ \\
\hline$\Sigma$ & $164.418,80$ & $5.841 .147 .054,08$ \\
\hline $\begin{array}{c}\text { MAD } \\
\text { dan } \\
\text { MSE }\end{array}$ & $\mathbf{2 3 . 4 8 8 , 4 0}$ & $\mathbf{8 3 4 . 4 4 9 . 5 7 9 , 1 5}$ \\
\hline
\end{tabular}

Tabel 9

Kesalahan peramalan metode Eksponential Smoothing $\alpha=0,1$

\begin{tabular}{|c|c|c|}
\hline Bul & $\begin{array}{c}\text { Dev. Abslut } \\
\mid \text { At }- \text { Ft } \mid\end{array}$ & $\begin{array}{c}\text { Error }^{2} \\
(\text { At }-\mathrm{Ft})^{2}\end{array}$ \\
\hline Jan & - & - \\
\hline Feb & $8.154,90$ & $66.502 .394,01$ \\
\hline Mar & $7.609,50$ & $57.904 .490,25$ \\
\hline Apr & 29597,4 & $876.006 .086,76$ \\
\hline Mei & $28.642,50$ & $820.392 .806,25$ \\
\hline Jun & 16996,5 & $288.881 .012,25$ \\
\hline Jul & 21987,9 & $483.467 .746,41$ \\
\hline Ags & $66.178,80$ & $4.379 .633 .569,44$ \\
\hline Sep & $1.252,80$ & $1.569 .507,84$ \\
\hline Okt & 13948,2 & $194.552 .283,24$ \\
\hline Nov & 1268,1 & $1.608 .077,61$ \\
\hline Des & 1086,3 & $1.180 .047,69$ \\
\hline$\Sigma$ & $122.718,60$ & $5.350 .892 .244,48$ \\
\hline $\begin{array}{c}\text { MAD } \\
\text { Man } \\
\text { MSE }\end{array}$ & $\mathbf{1 1 . 1 5 6 , 2 4}$ & $\mathbf{4 8 6 . 4 4 4 . 7 4 9 , 5 0}$ \\
\hline
\end{tabular}

Tabel 10

Kesalahan peramalan metode Eksponential Smoothing $\alpha=0,5$

\begin{tabular}{|c|c|c|}
\hline Bul & $\begin{array}{c}\text { Dev. Abslut } \\
\mid \text { At }-\mathrm{Ft} \mid\end{array}$ & $\begin{array}{c}\text { Error }^{2} \\
(\mathrm{At}-\mathrm{Ft})^{2}\end{array}$ \\
\hline Jan & - & - \\
\hline Feb & $4.530,50$ & $20.525 .430,25$ \\
\hline
\end{tabular}

\begin{tabular}{|c|c|c|}
\hline Mar & $4.227,50$ & $17.871 .756,25$ \\
\hline Apr & 16443 & $270.372 .249,00$ \\
\hline Mei & $15.912,50$ & $253.207 .656,25$ \\
\hline Jun & 9442,5 & $89.160 .806,25$ \\
\hline Jul & 12215,5 & $149.218 .440,25$ \\
\hline Ags & $36.766,00$ & $1.351 .738 .756,00$ \\
\hline Sep & 696,00 & $484.416,00$ \\
\hline Okt & 7749 & $60.047 .001,00$ \\
\hline Nov & 704,5 & $496.320,25$ \\
\hline $\begin{array}{c}\text { Des } \\
\Sigma\end{array}$ & 603,5 & $364.212,25$ \\
\hline $\begin{array}{c}\text { MAD } \\
\text { dan } \\
\text { MSE }\end{array}$ & $68.177,00$ & $1.651 .509 .952,00$ \\
\hline
\end{tabular}

Tabel 11

Kesalahan peramalan metode Eksponential Smoothing $\alpha=0,9$

\begin{tabular}{|c|c|c|}
\hline Bul & $\begin{array}{c}\text { Dev. Abslut } \\
\mid \text { At }- \text { Ft } \mid\end{array}$ & $\begin{array}{c}\text { Error }^{2} \\
(\mathrm{At}-\mathrm{Ft})^{2}\end{array}$ \\
\hline Jan & - & _- \\
\hline Feb & 906,10 & $821.017,21$ \\
\hline Mar & 845,50 & $714.870,25$ \\
\hline Apr & 3288,6 & $10.814 .889,96$ \\
\hline Mei & $3.182,50$ & $10.128 .306,25$ \\
\hline Jun & 1888,5 & $3.566 .432,25$ \\
\hline Jul & 2443,1 & $5.968 .737,61$ \\
\hline Ags & $7.353,20$ & $54.069 .550,24$ \\
\hline Sep & 139,20 & $19.376,64$ \\
\hline Okt & 1549,8 & $2.401 .880,04$ \\
\hline Nov & 140,9 & $19.852,81$ \\
\hline Des & 120,7 & $14.568,49$ \\
\hline$\Sigma$ & $13.635,40$ & $66.060 .398,08$ \\
\hline $\begin{array}{l}\text { MAD } \\
\text { dan } \\
\text { MSE }\end{array}$ & $1.239,58$ & $6.005 .490,73$ \\
\hline
\end{tabular}


Metode Peramalan yang tepat

Untuk mengetahui metode peramalan yang paling tepat adalah dengan cara membandingkan kesalahan peramalan dari masing masing metode peramalan.

Tabel 12

Perbandingan kesalahan peramalan

\begin{tabular}{|c|c|c|}
\hline Metode & MAD & MSE \\
\hline $\begin{array}{c}\text { Moving } \\
\text { Average } \\
3 \text { bulanan }\end{array}$ & $21.526,74$ & $686.998 .727,83$ \\
\hline $\begin{array}{c}\text { Moving } \\
\text { Average } \\
5 \text { bulanan }\end{array}$ & $23.488,40$ & $834.449 .579,15$ \\
\hline $\begin{array}{c}\text { Eksponen } \\
\text { tial } \\
\text { Smoothin } \\
g \alpha=0,1\end{array}$ & $11.156,24$ & $486.444 .749,50$ \\
\hline $\begin{array}{c}\text { Eksponen } \\
\text { tial }\end{array}$ & & \\
$\begin{array}{c}\text { Smoothin } \\
g \alpha=0,5\end{array}$ & $6.197,91$ & $150.137 .268,36$ \\
\hline $\begin{array}{c}\text { Eksponen } \\
\text { tial }\end{array}$ & & \\
$\begin{array}{c}\text { Smoothin } \\
g \alpha=0,9\end{array}$ & $1.239,58$ & $6.005 .490,73$ \\
\hline
\end{tabular}

\section{Kesimpulan}

Hasil peramalan dengan 2 metode alternatif dan ditambah perhitungan kesalahan peramalan dapat diambil kesimpulan bahwa peramalan permintaan konsumen dengan menggunakan metode Eksponential Smoothing $\alpha=0,9$ dikarenakan hasil perkiraan untuk permintaan konsumen periode januari sebesar 78.146,30 pcs lebih besar dari metode yang lainya. dan tingkat kesalahan peramalan MAD $=1.239,58$ dan MSE $=$ 6.005.490,73 lebih kecil dari metode yang lainya.

Saran untuk penelitian selanjutnya sebelum melakukan peramalan harus diketahui terlebih dahulu apa sebenarnya persoalan dalam pengambilan keputusan agar dapat mengetahui definisi tujuan dari peramalan tersebut dapat dilihat dengan waktu: yaitu: jangka pendek (Short Term), jangka Menengah (Medium Term) dan Jangka Panjang (Long Term).

\section{Referensi}

Andini. (2016). Peramalan Jumlah Stok Alat Tulis Kantor di UD Achmad Jaya menggunakan Metode Double Exponential Smoothing. Jurnal
Ilmiah Teknologi dan Informatika Asia (JITIKA). Vol. 10, No. 1, ISSN : 0852-730X. Februari 2016.

Herjanto. (2009). Manajemen Produksi dan Operasi. Jakarta: PT. Gramedia Widiasarana Indonesia.

Nasution. (2008). Perencanaan dan Pengendalian Produksi. Yogyakarta: Graha IImu.

Prasetio. (2014). Inventory Control Using Statistics Forecasting On Manufacture Company. Jurnal Informatika. Vol. II No. 2, September 2014.

Render, \& Heizer. (2009). Manajemen Operasi. Jakarta: Salemba Empat (PT. Salemba Emban Patria).

Setyowati. (2017). Penerapan Metode Single Exponential Smoothing dan Double Exponential Smoothing pada Peramalan Penjualan Pakaian. Artikel Skripsi. Universitas Nusantara PGRI Kediri, Januari 2017.

Siregar, A. (2009). Analisa Perbandingan Kinerja antara Algoritma Heuristic Pour dan Algoritma Nawaz, Enscore dan Ham (NEH) dalam menyelesaikan Penjadwalan Flowshop pada PT. Cakra Compact Aluminium Industries Medan. Teknik Industri.

Subagyo. (2008). Forecasting Konsep dan Aplikasi. Yogyakarta: BPFE.

Sulaksmi. (2014). Penjadwalan Produksi Dengan Algoritma Heuristic Pour ( Studi Kasus : Konveksi One Way Malang ). Jurnal INDD, Vol.15 No. 1 Februari 2014.

Taylor. (2009). Sains Manajemen 8th ed. Surabaya: Salemba Empat.

Wardah. (2016). Analisis Peramalan Penjualan Produk Keripik Pisang Kemasan Bungkus ( Studi Kasus: Home Industry Arwana Food Tembilahan). Jurnal Teknik Industri. Vol. XI No. 3, September 2016. 
Widodo. (2014). Pendekatan Algoritma Cross Entropy-Genetic Algorithm untuk menurunkan Makespan pada Penjadwalan FlowSHop. Jurnal Jemis, Universitas Brawijaya, Vol. 2, No. 1, Tahun 2014.

Yamit. (2008). Manajemen Produksi dan Operasi. Yogyakarta: Ekonesia Fakultas Ekonomi UII. 